\title{
Prediction models for different plaque morphology in non-significantly stenosed regions of saphenous vein grafts assessed with optical coherence tomography
}

\author{
Grzegorz M. Kubiak', Magdalena Dobrolińska², Elżbieta Pociask³ ${ }^{3}$, Wojciech Wańha², Paweł Gąsior², \\ Grzegorz Smolka², Andrzej Ochała², Wojciech Wojakowski², Tomasz Roleder ${ }^{4}$ \\ ${ }^{1}$ Department of Cardiac Surgery and Transplantology, SMDZ in Zabrze, Medical University of Silesia in Katowice, Silesian Centre for Heart \\ Disease, Zabrze, Poland \\ ${ }^{2} 3^{\text {rd }}$ Division of Cardiology and Structural Heart Diseases, Medical University of Silesia, Katowice, Poland \\ ${ }^{3}$ Krakow Cardiovascular Research Institute, Jagiellonian University Medical College, Krakow, Poland \\ ${ }^{4}$ Department of Cardiology, School of Health Sciences, Medical University of Silesia, Katowice, Poland
}

Adv Interv Cardiol 2018; 14, 4 (54): 363-372

DOI: https://doi.org/10.5114/aic.2018.79866

\begin{abstract}
A bstract
Introduction: Coronary artery bypass grafting $(C A B G)$ is a method of choice in treatment of diffuse coronary artery disease (CAD), although it has some limitations such as late saphenous vein graft (SVG) patency loss, which occurs in one fifth of all conduits at 5 years. Since atherosclerosis in SVG has diffuse characteristics, it appears that significantly and non-significantly stenosed lesions may have an equal impact on worse prognosis.

Aim: To assess non-significant lesions of SVG by the use of optical coherence tomography (OCT) and investigate the clinical and laboratory findings with the potential impact on plaque composition.

Material and methods: Twenty-nine patients with 43 non-significant lesions were enrolled in the study. All variables were assessed using uni- and multivariable logistic regression analysis with each plaque morphology as a dependent variable. Odds ratio $(\mathrm{OR})$ and $95 \%$ confidence interval $(\mathrm{Cl})$ were computed.

Results: Plaque rupture (PRT) was independently associated with age $(\mathrm{OR}=1.49,95 \% \mathrm{Cl}: 1.09-2.04, p=0.015)$ and lower rates of high-density lipoproteins $(\mathrm{HDL})$ cholesterol $(\mathrm{OR}=0.67,95 \% \mathrm{Cl}: 0.49-0.92, p=0.016)$. Intimal tearing or rupture (ITR) was related to reduced GFR (OR $=0.52,95 \% \mathrm{Cl}: 0.38-0.72, p=0.0004)$. Lipid-rich plaque (LRP) was associated with raised platelet count (PLT) $(\mathrm{OR}=1.51,95 \% \mathrm{Cl}: 1.16-1.96, p=0.004)$ and increased frequency of smoking $(\mathrm{OR}=1.45,95 \% \mathrm{Cl}: 1.12-1.89, p=0.007)$.

Conclusions: Atherosclerosis of SVG is not restricted to significantly stenosed lesions. Plaque composition is independently associated with different types of clinical and laboratory findings, mostly recognized as risk factors of CAD.
\end{abstract}

Key words: optical coherence tomography, coronary artery disease, saphenous vein graft coronary artery bypass grafting.

Su m m a ry

The current report focuses on optical coherence tomography imaging of the saphenous vein grafts (SVG) atherosclerosis in non-significantly stenosed regions of the vessel wall. It demonstrates that specific clinical features and laboratory findings, as assessed by multivariate logistic regression analysis, have potential impact on plaque composition in these regions of the SVG

\section{Introduction}

Coronary artery bypass grafting (CABG) is considered a method of choice in treatment of diffuse coronary artery disease (CAD) according to the current guidelines of revascularization and the reports from the SYNTAX trial [1-3]. The Medicare Provider and Analysis Review (MedPAR) database reported nearly 2.5 million CABGs performed between 1991 and 2005 in the United States (US) [4]. Despite the observed decline in the number of operations, the annual rate of CABGs dropped from 1742

Corresponding author:

Grzegorz M. Kubiak MD, Department of Cardiac Surgery and Transplantology, SMDZ in Zabrze, Medical University of Silesia, Silesian Centre for Heart Disease, 9 Curie-Skłodowska St, 41-800 Zabrze, Poland, phone: +48 3237338 57, e-mail: gkubiak@sccs.pl Received: 6.07.2018, accepted: 4.09.2018. 
in the years 2001-2002 to 1261 in the years 2005-2006, and the number of these procedures in the years 20072008 was still 1081 per million adults in the US (average data from 2 years) [5]. The trend of a reduced frequency of CABG is related to the advances in interventional cardiology which have been made in recent years by the introduction of drug-eluting stents (DES), advanced percutaneous coronary intervention (PCI) techniques (rotablation, bifurcation dedicated stents, mechanical circulatory devices) and innovations in pharmacological treatment [6-8]. Nevertheless, CABG is still needed in a vast amount of patients not suitable for $\mathrm{PCl}$. It is noteworthy that CABG poses many limitations, mainly related to the SVG late patency rate. Approximately $20 \%$ of saphenous vein grafts (SVGs) lose their patency at 5-year follow-up [9, 10], which is mostly caused by accelerated atherosclerosis. Risk factors of accelerated atherosclerosis are similar to those for native coronary atherosclerosis, but their relation to the SVG plaque composition was not described previously. Moreover, non-significant lesions are frequently associated with progression of the narrowing, which can manifest as acute coronary syndrome (ACS) [11, 12].

\section{Aim}

Therefore, the aim of the present study was to identify the variables with a potential impact on the SVG plaque type as assessed by optical coherence tomography (OCT) imaging.

\section{Material and methods}

\section{Study population}

Twenty-nine patients hospitalized in the Upper Silesia Medical Center between June 2013 and March 2016 were enrolled in the OCTOPUS registry $[13,14]$. The study complies with the Declaration of Helsinki and was accepted by the local ethical committee. Each patient gave his informed written content prior to enrollment. Inclusion criteria were as follows: CABG prior to intervention (SVG use mandatory), acute coronary syndrome, coronary artery disease with evidence of active ischemia in non-invasive testing. Exclusion criteria were as follows: lack of consent, ST-segment elevation myocardial infarction, less than 18 years of age, severe valvular insufficiency, contrast allergy, location of the lesion preventing safe examination. Lesions were defined as significant if they were involved in the initial manifestation of ACS assessed on the basis of clinical and non-invasive testing, and/or were quantitatively (QCA) assessed as 50\% stenosed or more. The other lesions were considered as non-significant and assigned for further analysis.

\section{OCT procedure and imaging technique}

The St Jude Ilumien Optis Medical system was used for OCT Imaging. The OCT Dragonfly catheter was ad- vanced through a guiding catheter over a 0.014 ' guidewire into the SVG via a $6 \mathrm{Fr}$ left radial or femoral approach. The OCT probe was positioned $5 \mathrm{~mm}$ distal to the lesion submitted to analysis. All OCT images were acquired using automatic pullback triggered by the hand injection of contrast flush. All patients were adequately heparinized with the activated clotting time (ACT) > $300 \mathrm{~s}$. The OCT image analysis was performed by an independent core laboratory at Krakow Cardiovascular Research Institute (www.KCRI.org). In case of a conflict of opinions the analyzed frame was excluded from the analysis. OCT analysis scrutinized serial images of the vessel at every $1 \mathrm{~mm}$ cross section (CS) for both significant and non-significant de novo SVG lesions. Cross-sectional area (CSA) and vessel lumen diameter were measured at every $1 \mathrm{~mm}$ in order to acquire the smallest values for both parameters, which were defined as minimal lumen diameter (MLD) and minimal CSA. They were assessed for both types of lesions. The OCT reference lumen area and reference diameter were estimated at the site of the largest CSA within the analyzed SVG for both de novo SVG lesions and non-significant lesions. Percentage lumen diameter and area stenosis were defined as the relative decrease in luminal diameter and CSA of the target lesion compared to the reference lumen diameter and CSA [15].

\section{OCT image analysis}

Tissue was classified as lipid for signal-poor regions with diffuse borders and high signal attenuation, homogeneous for signal-rich regions, calcified for signal-poor regions with sharp edges, and heterogeneous for poor signal regions without signal attenuation. The length of an arc of lipid and calcium that occupied the vessel wall circumference was measured and expressed in degrees $[16,17]$. The thickness of the fibrous cap that covered the lipid core was measured in the thinnest part of a signal-rich zone that separated the lipid content from the vessel lumen $(\mu \mathrm{m})$. The fibrous cap thickness was a mean value of three measurements. The OCT-defined thin-cap fibroatheroma (TCFA) was defined as a lipid-rich plaque (LRP) with fibrous cap thickness $<65 \mu \mathrm{m}$. Also, the presence of luminal thrombus, plaque rupture (PRT), intimal tear or rupture (ITR), friable tissue (FRB), calcified plaque (CAL) and the presence of venous valves were noted during the OCT analysis. An intimal tear was defined as a micro-cavity between the SVG lumen and its media, an intimal rupture as a micro-cavity of intima connected with the SVG lumen, tissue friability as a signal-free zone overlaid with signal-rich tissue inside the SVG wall [18]. Different types of SVG lesions are depicted in Figure 1. Offline OCT image analysis was performed using CAAS Intravascular 2.0 (Pie Medical Imaging BV). The quantitative OCT analysis was performed by three observers (GK, EP and TR). If a consensus could not be reached, the lesion was removed from 

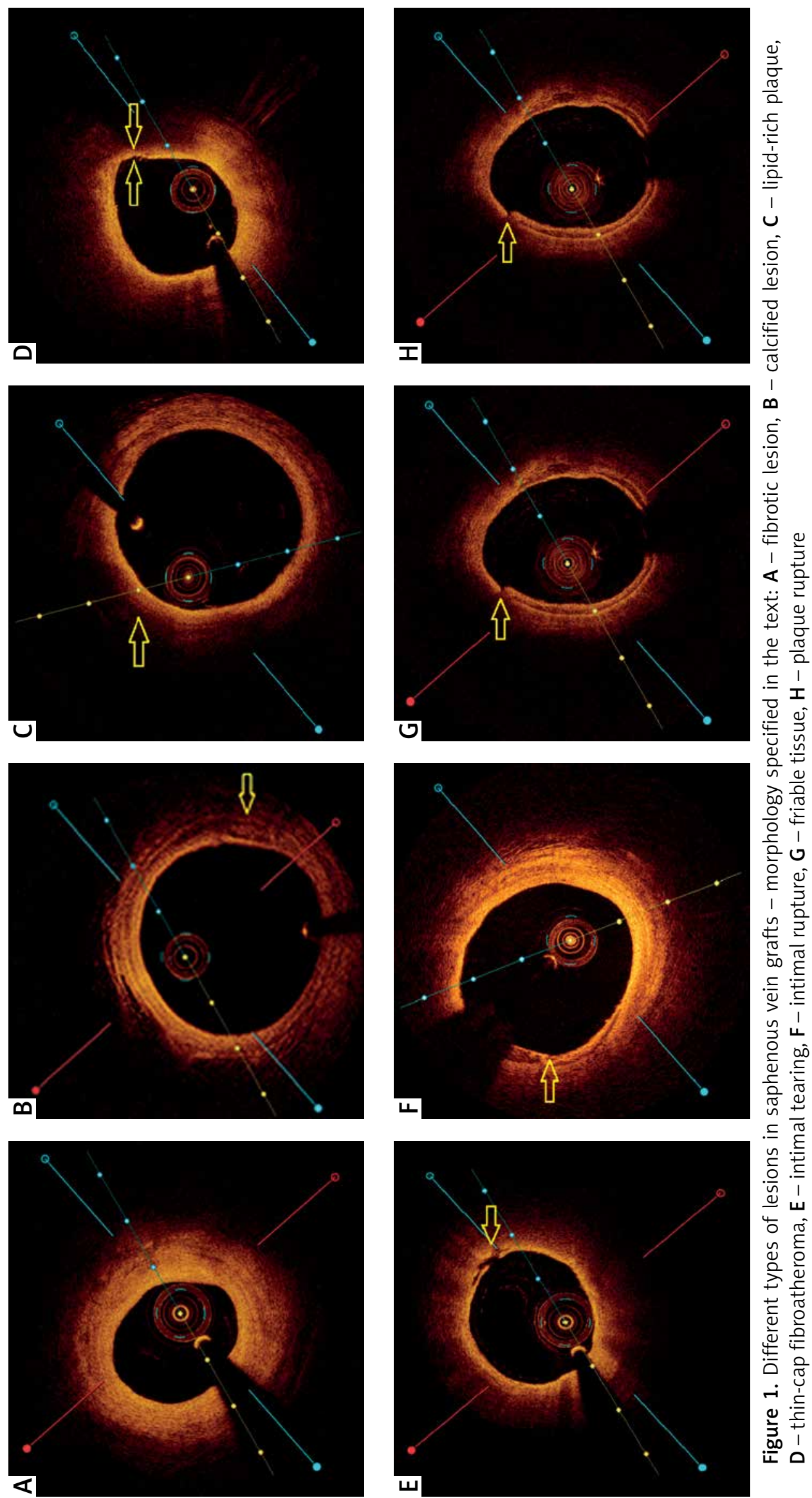

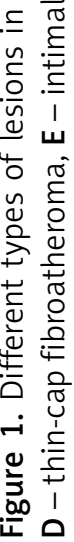


Table I. Patients' characteristics $(n=29)$

\begin{tabular}{|c|c|}
\hline Clinical data & Results \\
\hline Male, $n(\%)$ & $24(83)$ \\
\hline Age, mean \pm SD & $69.07 \pm 7.56$ \\
\hline Body mass index, median (IQR) $\left[\mathrm{kg} / \mathrm{m}^{2}\right]$ & $28.5(26-32)$ \\
\hline Non-ST elevated myocardial infarction, $n(\%)$ & $1(3)$ \\
\hline Unstable angina, $n(\%)$ & $10(35)$ \\
\hline Stable angina, $n(\%)$ & $18(62)$ \\
\hline \multicolumn{2}{|l|}{ Risk factors: } \\
\hline Hypertension, $n(\%)$ & $26(90)$ \\
\hline Current smoking, $n(\%)$ & $13(45)$ \\
\hline Hyperlipidemia, $n$ (\%) & $25(86)$ \\
\hline Diabetes, $n(\%)$ & $2(7)$ \\
\hline Time from CABG, median (IQR) [months] & $143(100-212)$ \\
\hline \multicolumn{2}{|l|}{ Number of saphenous vein grafts, $n(\%)$ : } \\
\hline 1 & $4(14)$ \\
\hline 2 & $18(62)$ \\
\hline 3 & $7(24)$ \\
\hline Arterial graft (LIMA-LAD), $n$ (\%) & $26(90)$ \\
\hline \multicolumn{2}{|l|}{ Pharmacological therapy, $n$ (\%): } \\
\hline$\beta$-Adrenergic antagonist & $25(86)$ \\
\hline Calcium channel antagonist & $4(14)$ \\
\hline Aspirin & $28(97)$ \\
\hline Thienopyridine & $2(7)$ \\
\hline Statin & $29(100)$ \\
\hline ARB/ACEI & $20(69)$ \\
\hline Other lipid-lowering therapy & $6(21)$ \\
\hline Insulin & $2(7)$ \\
\hline Oral antidiabetics & $5(17)$ \\
\hline \multicolumn{2}{|l|}{ Laboratory results: } \\
\hline GFR, median (IQR) $\left[\mathrm{ml} / \mathrm{min} / 1.73 \mathrm{~m}^{2}\right]$ & $71(53-88)$ \\
\hline White blood cells, median (IQR) $\left[\times 10^{3} / \mu \mathrm{l}\right]$ & $6.32(5.69-7.24)$ \\
\hline Platelets, median $(\mathrm{IQR})\left[\times 10^{3} / \mu \mathrm{I}\right]$ & $184(161-228)$ \\
\hline Hemoglobin, median (IQR) [mg/dl] & $14.08(12.90-15.22)$ \\
\hline Total cholesterol, mean \pm SD [mg/dl] & $162.29 \pm 58.52$ \\
\hline LDL cholesterol, median (IQR) [mg/dl] & $78(68-98)$ \\
\hline Triglyceride, median (IQR) [mg/dl] & $132(103-157)$ \\
\hline HDL cholesterol, median (IQR) [mg/dl] & $41(32-48)$ \\
\hline
\end{tabular}

$S D$ - standard deviation, $I Q R$ - interquartile range, $C A B G$ - coronary artery bypass grafting, LIMA-LAD - left internal mammary artery to left anterior descending artery, $A R B$ - angiotensin II receptor blocker, ACEI - angiotensin-converting-enzyme inhibitor, $L D L$ - low-density lipoproteins, $H D L$ - high-density lipoproteins, GFR - glomerular filtration rate. the analysis. The intraobserver variability for OCT quantitative measurements was presented previously [19].

\section{Statistical analysis}

Categorical variables are presented as counts and proportions, and the comparisons were performed using the $\chi^{2}$ test with Yates correction. The continuous variables are presented as the median and $25^{\text {th }}$ to $75^{\text {th }}$ percentile and mean \pm SD. Linear variables with normal distribution were compared using Student's t-test. Variables with abnormal distribution were compared using the Mann-Whitney $U$ test. All variables were assessed using univariable logistic regression analysis with each plaque morphology as a dependent variable. The odds ratio (OR) and $95 \%$ confidence interval $(\mathrm{Cl})$ were computed. The variables fulfilling the Akaike information criterion (AIC) described previously $[20,21]$ with $p<0.1$ were included in the primary multivariable logistic regression models of each plaque morphology occurrence. Additional adjustments for potential confounders were performed by the backward stepwise method, which enabled construction of the final multivariable logistic regression models of each plaque morphology occurrence. Differences between the values were considered statistically significant if $p<0.05$. Analyses were performed using Statistica 10 with the medical package (StatSoft Inc.).

\section{Results}

Twenty-nine patients with 32 de novo SVG significant and 43 non-significant lesions were included in the study. The data for clinical characteristics were analyzed on a per patient basis and the data on plaque morphology were analyzed per lesion. The number of non-significant is greater than significant lesions because in eleven cases the plaque composition was complex and presented more than one pathology. It necessitated the examination of an additional region of the vessel wall, which resulted in an increased number of analyzed regions. Percutaneous coronary intervention was performed in 22 of the de novo SVG lesions. For the patient characteristics and OCT-derived data please refer to Tables I and II respectively.

All the analyzed variables were included in the univariable logistic regression analysis of each plaque occurrence - the data are depicted in Tables III and IV.

The variables fulfilling the AIC (marked with an asterisk) were included in the multivariable logistic regression models. The obtained data from the multivariable logistic regression analysis, after exclusion of confounding factors (final models), were as follows: PRT was independently associated with age $(\mathrm{OR}=1.49,95 \% \mathrm{Cl}$ : 1.09-2.04, $p=0.015)$ and lower serum concentration of high-density lipoprotein $(\mathrm{HDL})$ cholesterol $(\mathrm{OR}=0.67$, $95 \% \mathrm{Cl}: 0.49-0.92, p=0.016)$. Intimal tear or rupture was related to reduced GFR $(\mathrm{OR}=0.52,95 \% \mathrm{Cl}: 0.38-0.72$, 
$p=0.0004)$. Lipid-rich plaque was associated with raised platelet count $(\mathrm{PLT})(\mathrm{OR}=1.51,95 \% \mathrm{Cl}: 1.16-1.96, p=$ $0.004)$ and increased frequency of smoking (OR $=1.45$, $95 \% \mathrm{Cl}: 1.12-1.89, p=0.007)$. The data are depicted in Figure 2.

On the other hand, FIB was independently associated with increased body surface area (BSA) (OR = 1.62, $95 \% \mathrm{Cl}: 1.25-2.10, p=0.001)$, decreased frequency of smoking (OR $=0.65,95 \% \mathrm{Cl}: 0.50-0.84, p=0.003)$ and hypertension ( $\mathrm{OR}=0.73,95 \% \mathrm{Cl}: 0.56-0.95, p=0.024)$. Calcified plaque was related to decreased serum concentration of total cholesterol (TCH) $(\mathrm{OR}=0.73,95 \% \mathrm{Cl}$ : $0.54-0.99, p=0.049)$ and more white blood cells (WBC) $(\mathrm{OR}=1.39,95 \% \mathrm{Cl}: 1.03-1.89, p=0.036)$. Friable tissue was related to increased frequency of smoking (OR = $1.61,95 \% \mathrm{Cl}: 1.17-2.22, p=0.006)$. The data are depicted in Figure 3.

\section{Discussion}

According to our best knowledge, we are the first to address the issue of the hypothetical impact of clinical and laboratory findings on different plaque morphologies assessed using OCT in non-significant lesions of SVGs. The novelties in the study are the highly selected group of CABG patients with SVGs and the use of advanced statistical techniques to construct a best matching prediction model of each plaque morphology. Several imaging modalities including coronary angiography (CAG) and intravascular ultrasound (IVUS) have shown no differences in plaque composition of native vessels in significant vs. non-significant lesions [22, 23]. The PROSPECT substudy investigators found significant differences among patients with vs. those without chronic kidney disease (CKD) considering the significantly increased necrotic core and dense calcium [24]. These observations, although performed in native coronary arteries, are in line with our findings that impaired renal function expressed as decreased GFR is independently associated with ITR occurrence (Figure 1). Kato et al. reported that GFR ( $\beta$ coefficient: $-6.0, p=0.034$ ) and diabetes ( $\beta$ coefficient: 461.7.0, $p<0.001$ ) were independently associated with lipid index in the uni- and multivariate linear regression models [25]. These findings are coherent with our data; however, in our group only 2 patients had diabetes, which suggests that this aspect was statistically underpowered. Nasu et al. observed a positive correlation between low-density lipoprotein (LDL) cholesterol, the percentage of necrotic core volume $(r=0.520$, $p<0.0001)$ and TCFA incidence [26]. Moreover they found, although the difference was statistically insignificant, that HDL cholesterol is decreased in patients with definite TCFA compared to those without (47.5 vs. 54.0, $p=0.39$ ). These data are in agreement with our findings that decreased HDL cholesterol is independently associated with the incidence of PRT $(\mathrm{OR}=0.67,95 \% \mathrm{Cl}$ :
Table II. Optical coherence tomography derived data concerning plaque characteristics

\begin{tabular}{|c|c|}
\hline Optical coherence tomography findings & $\begin{array}{c}\text { Non-signifi- } \\
\text { cantly stenosed } \\
\text { lesions }(n=43)\end{array}$ \\
\hline Region of interest, median (IQR) [mm] & $11.2(8.0-13.2)$ \\
\hline Ref. lumen CSA, median (IQR) [ $\left.\mathrm{mm}^{2}\right]$ & $7.5(5.6-8.7)$ \\
\hline Ref. mean lumen diameter, median (IQR) [mm] & $3.1(2.7-3.3)$ \\
\hline Minimal lesion lumen CSA $\left[\mathrm{mm}^{2}\right]$ & NA \\
\hline Minimal lumen diameter, median (IQR) [mm] & $2.8(2.5-3.1)$ \\
\hline Area stenosis, median (IQR) [\%] & $15.0(13.0-17.0)$ \\
\hline Diameter stenosis, median (IQR) [\%] & $0.0(0.0-5.0)$ \\
\hline Maximal cap thickness, median (IQR) [ $\mu \mathrm{m}]$ & $140.0(125-155)$ \\
\hline Maximal lipid arc, median (IQR) [º] & $94.0(75-120)$ \\
\hline Maximal calcification arc, median (IQR) $\left[^{\circ}\right]$ & $107.5(74.0-144.0)$ \\
\hline Plaque calcification, $n$ (\%) & $16(37)$ \\
\hline TCFA, $n(\%)$ & $0(0)$ \\
\hline Thrombus, $n(\%)$ & $0(0)$ \\
\hline Heterogeneous tissue, $n$ (\%) & $4(9)$ \\
\hline Plaque rupture, $n(\%)$ & $4(9)$ \\
\hline Lipid-rich plaque, $n(\%)$ & $15(35)$ \\
\hline Dissection, $n(\%)$ & $0(0)$ \\
\hline Intimal tearing, $n(\%)$ & $2(5)$ \\
\hline Intimal rupture, $n$ (\%) & $3(7)$ \\
\hline Tissue friability, $n$ (\%) & $2(5)$ \\
\hline Plaque within the SVG valve, $n$ (\%) & $0(0)$ \\
\hline
\end{tabular}

CSA - cross sectional area, IOR - interquartile range, NA - not applicable, Ref. - reference, TCFA - thin-cap fibroatheroma, SVG - saphenous vein graft.

0.49-0.92, $p=0.016)$. Decreased TCH was independently associated with calcified plaque occurrence, which is in line with data from previously published large registries performed in patients with ACS $[27,28]$. The hypercholesterolemia paradox is a widely observed phenomenon of better outcomes in the post-ACS group of patients with raised $\mathrm{TCH}$ [29]. Statin therapy, more frequent medical contact prior to index disease and younger age are among possible triggers of this state [30]. In our group, all patients received statins and the correlation of TCH with age was statistically insignificant $(r=-0.12$, $p=0.56$ - data not shown). Coolong et al. assessed the incidence of major adverse cardiac events (MACE) after stenting of SVG with embolic protection devices in different trials published between 2002 and 2005. They found that smoking $(\mathrm{OR}=1.50,95 \% \mathrm{Cl}: 1.08-2.08, p=0.01)$ and increased age per 10 years $(\mathrm{OR}=1.21,95 \% \mathrm{Cl}$ : 1.07-1.37, $p=0.01$ ) are among independent predictors of 30-day MACE [31]. The relation between smoking and the 
Table III. Univariable logistic regression analysis of multiple determinants on each plaque morphology

\begin{tabular}{|c|c|c|c|}
\hline Parameter & $\begin{array}{c}\text { PRT }(n=4) \\
\text { Odds ratio }(95 \% \mathrm{Cl}), p \text {-value }\end{array}$ & $\begin{array}{c}\text { ITR }(n=5) \\
\text { Odds ratio }(95 \% \mathrm{Cl}), p \text {-value }\end{array}$ & $\begin{array}{c}\operatorname{LRP}(n=15) \\
\text { Odds ratio }(95 \% \mathrm{Cl}), p \text {-value }\end{array}$ \\
\hline EEM vol. [mm] & $0.91(0.66-1.24), 0.531$ & $0.92(0.67-1.25), 0.586$ & 1.25 (0.92-1.69), 0.153 \\
\hline Lumen vol. [mm] & 0.94 (0.69-1.28), 0.692 & 0.92 (0.68-1.26), 0.617 & 1.23 (0.91-1.67), 0.178 \\
\hline Min. av. lum. diam [mm] & $1.19(0.87-1.61), 0.276$ & 1.12 (0.82-1.53), 0.471 & 1.14 (0.84-1.55), 0.401 \\
\hline Min. lum. area $\left[\mathrm{mm}^{2}\right]$ & $1.18(0.87-1.61), 0.289$ & 1.11 (0.81-1.51), 0.519 & 1.13 (0.83-1.55), 0.423 \\
\hline Min. lum. diam. [mm] & 1.13 (0.83-1.55), 0.419 & 1.03 (0.75-1.41), 0.857 & 1.22 (0.90-1.66), 0.197 \\
\hline Plaque vol. [mm] & 0.82 (0.61-1.12), 0.209 & 0.91 (0.67-1.24), 0.536 & $1.26(0.93-1.71), 0.130$ \\
\hline Stenosis EEM [\%] & $0.93(0.68-1.27), 0.640$ & 0.91 (0.66-1.24), 0.530 & 0.99 (0.72-1.35), 0.928 \\
\hline Stenosis length [mm] & 0.77 (0.57-1.05), $0.096^{*}$ & 0.85 (0.62-1.16), 0.297 & 1.24 (0.91-1.68), 0.170 \\
\hline Stenosis reference [\%] & 0.86 (0.63-1.17), 0.332 & 0.83 (0.61-1.13), 0.240 & $1.23(0.90-1.67), 0.187$ \\
\hline Surf msr. TLP $\left[\mathrm{mm}^{2}\right]$ & 0.85 (0.62-1.15), 0.284 & $0.89(0.65-1.21), 0.450$ & 1.27 (0.94-1.72), 0.125 \\
\hline Age [years] & $1.31(0.97-1.79), 0.084^{*}$ & 1.37 (1.01-1.85), $0.047^{*}$ & 1.20 (0.88-1.65), 0.250 \\
\hline Body surface area $\left[\mathrm{m}^{2}\right]$ & 0.79 (0.56-1.13), 0.196 & 1.35 (0.95-1.90), $0.094^{*}$ & 0.93 (0.65-1.33), 0.676 \\
\hline $\mathrm{BMI}\left[\mathrm{kg} / \mathrm{m}^{2}\right]$ & 0.80 (0.56-1.13), 0.201 & $0.93(0.65-1.33), 0.690$ & 1.00 (0.70-1.44), 0.983 \\
\hline LVEF [\%] & 0.94 (0.69-1.29), 0.714 & $0.58(0.45-0.76),<0.001^{*}$ & 1.12 (0.82-1.53), 0.457 \\
\hline Troponin [ng/l] & 0.86 (0.60-1.24), 0.415 & 1.42 (1.01-1.99), 0.051* & 1.21 (0.84-1.73), 0.298 \\
\hline $\mathrm{HGB}[\mathrm{mg} / \mathrm{dll}]$ & $0.91(0.66-1.25), 0.563$ & 0.95 (0.69-1.31), 0.773 & 0.94 (0.68-1.29), 0.694 \\
\hline WBC $\left[10^{3} / \mu \mathrm{l}\right]$ & 1.11 (0.81-1.53), 0.519 & 1.08 (0.78-1.49), 0.632 & 1.04 (0.76-1.43), 0.802 \\
\hline $\mathrm{PLT}\left[10^{3} / \mu \mathrm{l}\right]$ & $1.12(0.82-1.54), 0.466$ & 0.94 (0.68-1.30), 0.712 & 1.59 (1.20-2.11), $0.002^{*}$ \\
\hline $\mathrm{TCH}[\mathrm{mg} / \mathrm{dll}]$ & $0.93(0.66-1.30), 0.668$ & $0.63(0.47-0.85), 0.004^{*}$ & 1.13 (0.81-1.58), 0.473 \\
\hline $\mathrm{TG}[\mathrm{mg} / \mathrm{dl}]$ & $1.18(0.84-1.65), 0.337$ & 0.74 (0.53-1.02), $0.070^{*}$ & 0.97 (0.69-1.37), 0.858 \\
\hline $\mathrm{LDL}[\mathrm{mg} / \mathrm{dl}]$ & $0.92(0.66-1.29), 0.621$ & $0.84(0.60-1.17), 0.308$ & 1.08 (0.77-1.51), 0.646 \\
\hline $\mathrm{HDL}[\mathrm{mg} / \mathrm{dl}]$ & 1.86 (1.35-2.57), $0.058^{*}$ & 0.96 (0.68-1.34), 0.801 & 0.98 (0.70-1.37), 0.897 \\
\hline Creatinine $[\mathrm{mg} / \mathrm{dl}]$ & 1.12 (0.81-1.54), 0.498 & 1.28 (0.93-1.75), 0.127 & $0.86(0.62-1.18), 0.346$ \\
\hline GFR $\left[\mathrm{ml} / \mathrm{min} / 1.73 \mathrm{~m}^{2}\right]$ & 0.94 (0.68-1.30), 0.702 & $0.57(0.44-0.75),<0.001^{*}$ & 1.14 (0.82-1.57), 0.428 \\
\hline Male & 0.95 (0.69-1.30), 0.737 & 0.99 (0.72-1.35), 0.934 & 0.76 (0.56-1.02), $0.072^{*}$ \\
\hline Diabetes & 0.85 (0.62-1.15), 0.283 & 1.07 (0.78-1.46), 0.683 & 1.03 (0.76-1.41), 0.840 \\
\hline Hypertension & 1.14 (0.83-1.55), 0.410 & 1.16 (0.85-1.58), 0.350 & 1.34 (1.00-1.81), $0.055^{\star}$ \\
\hline Current smoking & 0.90 (0.66-1.23), 0.513 & 1.14 (0.84-1.56), 0.393 & 1.55 (1.17-2.05), 0.003* \\
\hline
\end{tabular}

$P R T$ - plaque rupture, ITR - intimal tearing or rupture, LRP-lipid-rich plaque, EEM - external elastic membrane, TLP-total lumen perimeter, BMI-body mass index, LVEF - left ventricular ejection fraction, HGB - hemoglobin, WBC - white blood cells, PLT - platelets, TCH - total cholesterol, TG - triglycerides, LDL - low-density lipoproteins, HDL - high-density lipoproteins, GFR - glomerular filtration rate.

progression of intermediate SVG lesions into severely stenosed lesions during a median of 35 months of follow-up was also reported by Abdel-Karim et al. [11]. These findings are in line with our results which revealed that smoking was an independent predictor of FRB and LRP occurrence.

\section{Study limitations}

We cannot conclude definitively whether this advanced technology could contribute to clinical practice in this demanding group of patients because we did not correlate the OCT findings with the clinical endpoints. Moreover, the number of study participants is relatively small and the investigation was performed in a single center. However, the researchers did not interfere with the management process at any stage. It is noteworthy that, since OCT is an invasive procedure, there exists a theoretical possibility of iatrogenic damage of the vessel wall, which might have influenced the results. Consid- 
Table IV. Univariable logistic regression analysis of multiple determinants on each plaque morphology

\begin{tabular}{|c|c|c|c|}
\hline Paramter & $\begin{array}{c}\text { FIB }(n=27) \\
\text { Odds ratio }(95 \% \mathrm{Cl}), p \text {-value }\end{array}$ & $\begin{array}{l}\text { CAL }(n=16) \\
\text { Odds ratio }(95 \% \mathrm{Cl}), p \text {-value }\end{array}$ & $\begin{array}{c}\text { FRB }(n=2) \\
\text { Odds ratio }(95 \% \mathrm{Cl}), p \text {-value }\end{array}$ \\
\hline EEM vol. $[\mathrm{mm}]$ & 1.01 (0.74-1.38), 0.960 & 0.93 (0.68-1.27), 0.655 & 0.83 (0.61-1.13), 0.225 \\
\hline Lumen vol. [mm] & 0.98 (0.72-1.34), 0.885 & 0.96 (0.70-1.31), 0.800 & 0.84 (0.62-1.15), 0.275 \\
\hline Min. av. lum. diam [mm] & $0.91(0.67-1.25), 0.558$ & 1.23 (0.91-1.67), 0.181 & 0.95 (0.69-1.30), 0.738 \\
\hline Min. lum. area $\left[\mathrm{mm}^{2}\right]$ & 0.94 (0.69-1.28), 0.673 & 1.19 (0.87-1.61), 0.274 & 0.95 (0.69-1.29), 0.733 \\
\hline Min. lum. diam. [mm] & 0.89 (0.65-1.21), 0.448 & 1.18 (0.86-1.60), 0.299 & 0.94 (0.69-1.28), 0.689 \\
\hline Plaque vol. [mm] & $1.10(0.81-1.51), 0.529$ & 0.86 (0.63-1.17), 0.328 & 0.80 (0.59-1.08), 0.150 \\
\hline Stenosis EEM [\%] & 1.19 (0.88-1.62), 0.257 & 0.86 (0.63-1.16), 0.316 & 0.87 (0.64-1.18), 0.359 \\
\hline Stenosis length [mm] & 1.05 (0.77-1.43), 0.759 & 0.81 (0.60-1.10), 0.176 & 0.84 (0.62-1.14), 0.263 \\
\hline Stenosis reference [\%] & 0.98 (0.72-1.34), 0.898 & 0.79 (0.58-1.07), 0.134 & 0.98 (0.72-1.34), 0.883 \\
\hline Surf msr. TLP $\left[\mathrm{mm}^{2}\right]$ & 1.02 (0.75-1.39), 0.897 & 0.90 (0.66-1.22), 0.484 & 0.82 (0.61-1.12), 0.211 \\
\hline Age [years] & 0.93 (0.68-1.28), 0.648 & 1.28 (0.94-1.74), 0.122 & 1.16 (0.85-1.59), 0.352 \\
\hline Body surface area $\left[\mathrm{m}^{2}\right]$ & 1.53 (1.11-2.12), 0.014* & 0.95 (0.66-1.36), 0.764 & 0.81 (0.57-1.16), 0.248 \\
\hline BMI $\left[\mathrm{kg} / \mathrm{m}^{2}\right]$ & 1.28 (0.91-1.82), 0.161 & 0.77 (0.54-1.08), 0.133 & $0.89(0.62-1.27), 0.520$ \\
\hline LVEF [\%] & 0.85 (0.62-1.16), 0.300 & 0.91 (0.66-1.24), 0.534 & 1.05 (0.77-1.43), 0.755 \\
\hline Troponin [ng/l] & 0.80 (0.56-1.15), 0.230 & $1.13(0.78-1.62), 0.512$ & $1.36(0.96-1.93), 0.083^{*}$ \\
\hline $\mathrm{HGB}[\mathrm{mg} / \mathrm{dl}]$ & 1.06 (0.77-1.46), 0.708 & 0.81 (0.59-1.11), 0.184 & $0.91(0.66-1.26), 0.575$ \\
\hline WBC $\left[10^{3} / \mu \mathrm{l}\right]$ & 0.94 (0.68-1.29), 0.697 & $1.35(0.99-1.83), 0.057^{\star}$ & 0.96 (0.70-1.32), 0.795 \\
\hline $\mathrm{PLT}\left[10^{3} / \mu \mathrm{l}\right]$ & 0.75 (0.55-1.02), $0.067^{*}$ & 0.95 (0.69-1.30), 0.739 & 0.94 (0.68-1.30), 0.704 \\
\hline $\mathrm{TCH}[\mathrm{mg} / \mathrm{dl}]$ & 0.78 (0.56-1.09), 0.147 & $0.71(0.52-0.98), 0.040^{*}$ & $1.08(0.77-1.52), 0.634$ \\
\hline $\mathrm{TG}[\mathrm{mg} / \mathrm{dl}]$ & $0.66(0.48-0.91), 0.013^{*}$ & 1.01 (0.72-1.43), 0.939 & 1.15 (0.82-1.61), 0.423 \\
\hline $\operatorname{LDL}[\mathrm{mg} / \mathrm{dl}]$ & 0.80 (0.58-1.12), 0.195 & 0.87 (0.63-1.22), 0.428 & 1.04 (0.74-1.45), 0.833 \\
\hline $\mathrm{HDL}[\mathrm{mg} / \mathrm{dl}]$ & $1.35(0.98-1.86), 0.072^{*}$ & $0.68(0.49-0.92), 0.016^{\star}$ & 1.00 (0.71-1.40), 0.980 \\
\hline Creatinine $[\mathrm{mg} / \mathrm{dl}]$ & $1.21(0.88-1.67), 0.230$ & 1.02 (0.74-1.41), 0.911 & 0.85 (0.62-1.17), 0.315 \\
\hline GFR $\left[\mathrm{ml} / \mathrm{min} / 1.73 \mathrm{~m}^{2}\right]$ & 0.90 (0.65-1.24), 0.510 & 0.83 (0.61-1.15), 0.260 & 1.00 (0.72-1.38), 0.996 \\
\hline Male & $1.64(1.25-2.16), 0.001^{*}$ & 1.00 (0.73-1.36), 0.985 & $0.63(0.48-0.83), 0.002^{*}$ \\
\hline Diabetes & 0.84 (0.62-1.14), 0.263 & 1.08 (0.79-1.48), 0.618 & 1.24 (0.91-1.68), 0.165 \\
\hline Hypertension & 0.73 (0.55-0.99), 0.043* & 1.36 (1.01-1.83), $0.043^{*}$ & 1.09 (0.80-1.49), 0.571 \\
\hline Current smoking & $0.66(0.50-0.88), 0.006^{*}$ & 0.92 (0.68-1.26), 0.606 & 1.36 (1.01-1.83), $0.043^{*}$ \\
\hline
\end{tabular}

FIB - fibrotic plaque, CAL - calcified plaque, FRB - friable tissue, other abbreviations as in Table III.

ering these facts, we believe further studies are warranted in this field.

\section{Conclusions}

Clinical and laboratory findings have an impact on plaque composition of non-significant lesions assessed with OCT. Saphenous vein graft endothelial pathology of non-significant lesions is associated with risk factors of CAD such as smoking, impaired renal function, elderly age, decreased HDL and raised PLT.

\section{Acknowledgments}

This work was supported by European Union structural funds (Innovative Economy Operational Program POIG.01.01.02-00-109/09-00) and statutory funds of the Medical University of Silesia.

\section{Conflict of interest}

The authors declare no conflict of interest. 


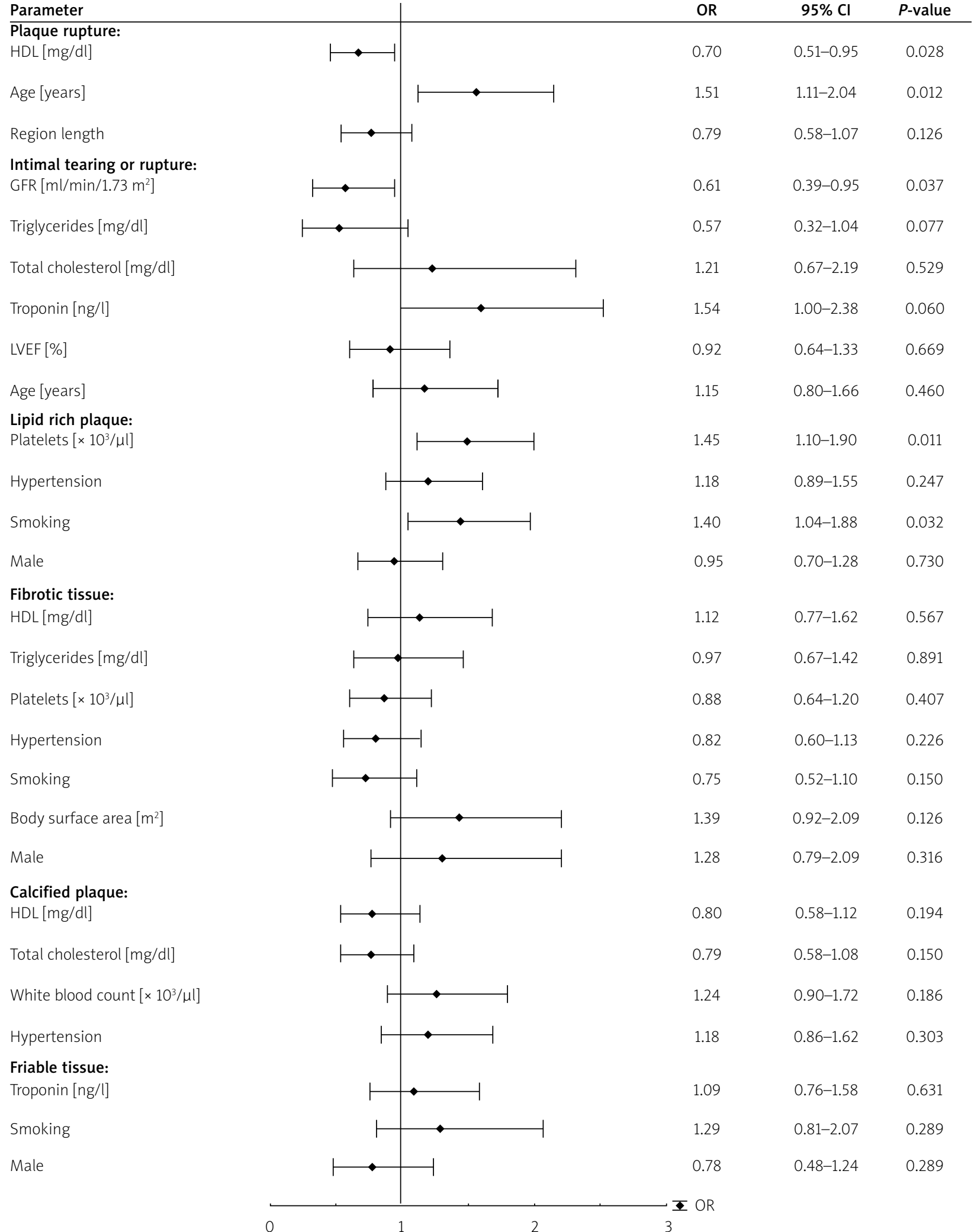

Figure 2. Logistic regression primary models of OCT-based prediction for different plaque types $H D L$ - high-density lipoproteins, GFR - glomerular filtration rate, LVEF - left ventricular ejection fraction. 


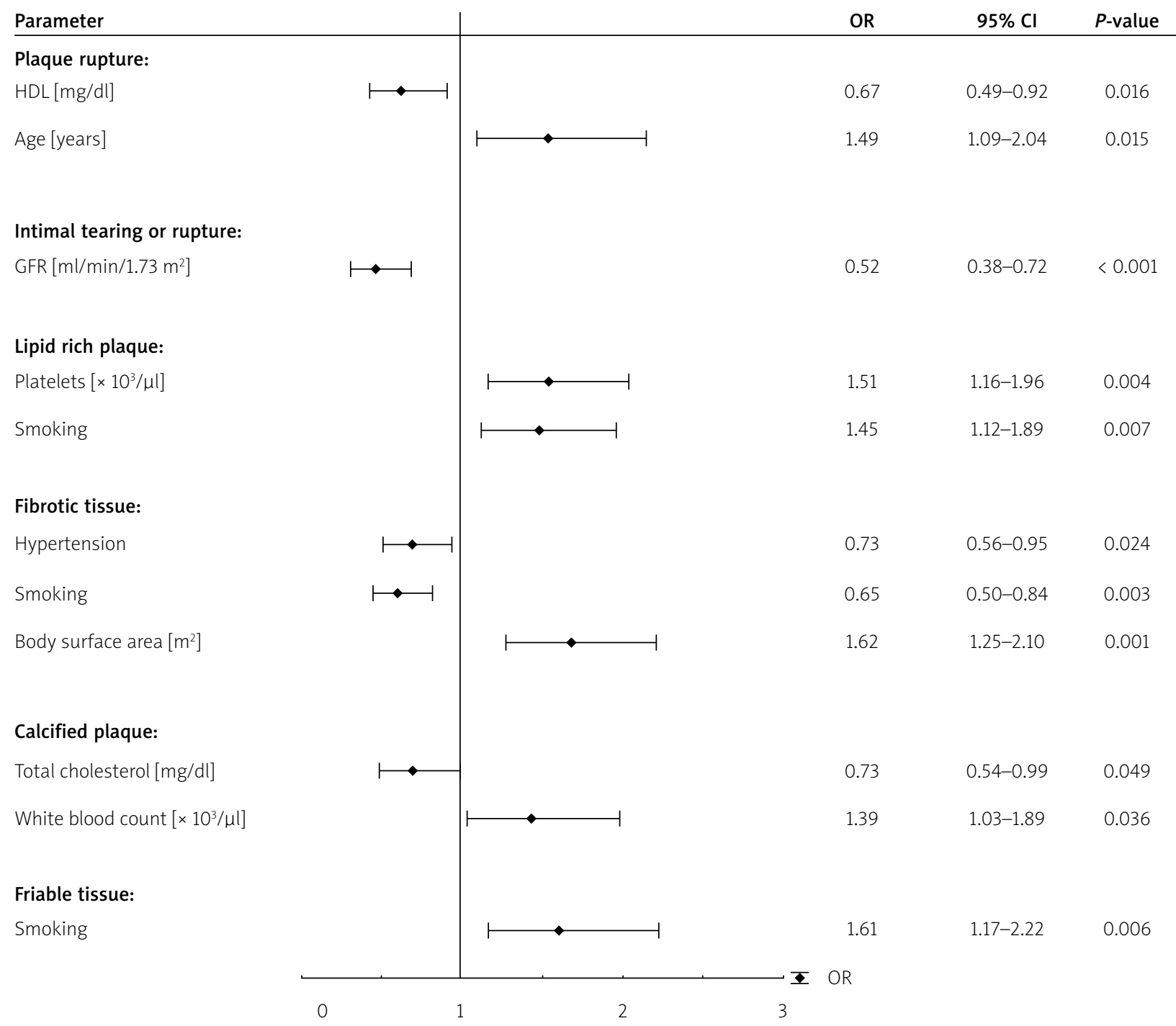

Figure 3. Logistic regression secondary models of OCT-based prediction for different plaque types $H D L$ - high-density lipoproteins, GFR - glomerular filtration rate.

\section{References}

1. Authors/Task Force members; Windecker S, Kolh P, Alfonso F, et al. 2014 ESC/EACTS Guidelines on Myocardial Revascularization: The Task Force on Myocardial Revascularization of the European Society of Cardiology (ESC) and the European Association for Cardio-Thoracic Surgery (EACTS) Developed with the Special Contribution of the European Association of Percutaneous Cardiovascular Interventions (EAPCI). Eur Heart J 2014; 35: 2541-619.

2. Serruys PW, Morice MC, Kappetein AP, et al. SYNTAX Investigators. Percutaneous coronary intervention versus coronary-artery bypass grafting for severe coronary artery disease. N Engl J Med 2009; 360: 961-72.

3. Lee TH, Hillis LD, Nabel EG. CABG vs. stenting: clinical implications of the SYNTAX trial. N Engl I Med 2009; 360: e10.

4. Hockenberry J, Lu X, Vaughan-Sarrazin MS, et al. Shifts in surgical revascularization and valve procedures among medicare beneficiaries. Med Care 2011; 49: 686-92.
5. Epstein AJ, Polsky D, Yang F, et al. Coronary revascularization trends in the United States, 2001-2008. JAMA 2011; 305: 1769-76.

6. Ohman EM, Nanas J, Stomel RJ, et al. TACTICS Trial. Thrombolysis and counterpulsation to improve survival in myocardial infarction complicated by hypotension and suspected cardiogenic shock or heart failure: results of the TACTICS Trial. J Thromb Thrombolysis 2005; 19: 33-9.

7. Seyfarth M, Sibbing D, Bauer I, et al. A randomized clinical trial to evaluate the safety and efficacy of a percutaneous left ventricular assist device versus intra-aortic balloon pumping for treatment of cardiogenic shock caused by myocardial infarction. J Am Coll Cardiol 2008; 52: 1584-8.

8. Schiller P, Vikholm P, Hellgren L. The Impella ${ }^{\oplus}$ recover mechanical assist device in acute cardiogenic shock: a single-centre experience of 66 patients. Interact Cardiovasc Thorac Surg 2016; 22: 452-8.

9. Bourassa MG, Fisher LD, Campeau L, et al. Long-term fate of bypass grafts: the Coronary Artery Surgery Study (CASS) and Montreal Heart Institute Experiences. Circulation 1985; 72: V71-8. 
10. Fitzgibbon GM, Kafka HP, Leach AJ, et al. Coronary bypass graft fate and patient outcome: angiographic follow-up of 5,065 grafts related to survival and reoperation in 1,388 patients during 25 years. J Am Coll Cardiol 1996; 28: 616-26.

11. Abdel-Karim AR, Da Silva M, Lichtenwalter C, et al. Prevalence and outcomes of intermediate saphenous vein graft lesions: findings from the stenting of saphenous vein grafts randomized-controlled trial. Int J Cardiol 2013; 168: 2468-73.

12. Kim FY, Marhefka G, Ruggiero NJ, et al. Saphenous vein graft disease: review of pathophysiology, prevention, and treatment. Cardiol Rev 2013; 21: 101-9.

13. Roleder T, Wanha W, Smolka G, et al. Bioresorbable vascular scaffolds in saphenous vein grafts (data from OCTOPUS Registry). Adv Interv Cardiol 2015; 11: 323-6.

14. Roleder T, Pociask E, Wańha W, et al. Optical coherence tomography of de novo lesions and in-stent restenosis in coronary saphenous vein grafts (OCTOPUS Study). Circ J 2016; 80: 1804-11.

15. Ali ZA, Roleder T, Narula J, et al. Increased thin-cap neoatheroma and periprocedural myocardial infarction in drug-eluting stent restenosis: multimodality intravascular imaging of drug-eluting and bare-metal stents. Circ Cardiovasc Interv 2013; 6: 507-17.

16. Yabushita H, Bouma BE, Houser SL, et al. Characterization of human atherosclerosis by optical coherence tomography. Circulation 2002; 106: 1640-5.

17. Kim JS, Afari ME, Ha J, et al. Neointimal patterns obtained by optical coherence tomography correlate with specific histological components and neointimal proliferation in a swine model of restenosis. Eur Heart J Cardiovasc Imaging 2014; 15: 292-8.

18. Davlouros P, Damelou A, Karantalis V, et al. Evaluation of culprit saphenous vein graft lesions with optical coherence tomography in patients with acute coronary syndromes. JACC CardiovasC Interv 2011; 4: 683-93.

19. Kochman J, Tomaniak M, Kołtowski $Ł$, et al. A 12-month angiographic and optical coherence tomography follow-up after bioresorbable vascular scaffold implantation in patients with ST-segment elevation myocardial infarction. Catheter Cardiovasc Interv 2015; 86: E180-9.

20. Bozdogan H. Model selection and Akaike's information criterion (AIC): the general theory and its analytical extensions. Psychometrika 1987; 52: 345-70.

21. Akaike $\mathrm{H}$. Information theory and an extension of the maximum likelihood principle. In: Second International Symposium on Information Theory. Petrov BN, Csaki F (eds.). Academiai Kiado, Budapest 1973; 267-81.

22. Goldstein JA, Demetriou D, Grines CL, et al. Multiple complex coronary plaques in patients with acute myocardial infarction. N Engl J Med 2000; 343: 915-22.

23. Maehara A, Mintz GS, Bui AB, et al. Morphologic and angiographic features of coronary plaque rupture detected by intravascular ultrasound. J Am Coll Cardiol 2002; 40: 904-10.

24. Baber U, Stone GW, Weisz G, et al. Coronary plaque composition, morphology, and outcomes in patients with and without chronic kidney disease presenting with acute coronary syndromes. JACC Cardiovasc Imaging 2012; 5 (3 Suppl): S53-61.

25. Kato K, Yonetsu T, Jia H, et al. Nonculprit coronary plaque characteristics of chronic kidney disease. Circ Cardiovasc Imaging 2013; 6: 448-56.

26. Nasu K, Terashima M, Habara M, et al. Impact of cholesterol metabolism on coronary plaque vulnerability of target vessels: a combined analysis of virtual histology intravascular ultra- sound and optical coherence tomography. JACC Cardiovasc Interv 2013; 6: 746-55.

27. Martin SS, Faridi KF, Joshi PH, et al. Remnant lipoprotein cholesterol and mortality after acute myocardial infarction: further evidence for a hypercholesterolemia paradox from the TRIUMPH Registry. Clin Cardiol 2015; 38: 660-7.

28. Quinones PA, Kirchberger I, Amann U, et al. Does marital status contribute to the explanation of the hypercholesterolemia paradox in relation to long term mortality in myocardial infarction? Findings from the MONICA/KORA Myocardial Infarction Registry. Prev Med 2015; 75: 25-31.

29. Kalantar-Zadeh K, Horwich TB, Oreopoulos A, et al. Risk factor paradox in wasting diseases. Curr Opin Clin Nutr Metab Care 2007; 10: 433-42.

30. Wang TY, Newby LK, Chen AY, et al. Hypercholesterolemia paradox in relation to mortality in acute coronary syndrome. Clin Cardiol 2009; 32: E22-8.

31. Coolong A, Baim DS, Kuntz RE, et al. Saphenous vein graft stenting and major adverse cardiac events: a predictive model derived from a pooled analysis of 3958 patients. Circulation 2008; 117: 790-7. 